\title{
INFLUENCE OF METAL VERSUS TRANSPARENT MATRICES ON PROXIMAL CONTACT TIGHTNESS OF CLASS II BULK-FILL COMPOSITE RESTORATIONS
}

\author{
Hassan El-Shamy*
}

\begin{abstract}
Purpose: This study investigated the effect of metal versus transparent matrix systems on proximal contact tightness (PCT) of class II bulk-fill composite resin restorations.

Methods: 80 Ivorine teeth with standardized MO cavity preparations were randomly divided into 4 equal groups $(n=20)$. Group1; sectional metal matrix, group2; pre-contoured circumferential metal matrix in a Tofflemire retainer, group3; conventional metal matrix in a Tofflemire retainer, and group4; Blue Cure-Thru transparent contoured matrix band. All matrices were combined with a separation ring and secured with wooden wedges. Cavity preparations were restored with bulkfill composite resin; SonicFill 2 with the corresponding bonding system following manufacturer's instructions. Composite material cured for 20s using Elipar S10 light curing unit. Teeth were restored in a clinically relevant situation using KaVo manikin head. After matrix and wedge removal, proximal contact tightness was measured using the Tooth Pressure Meter. Means were calculated and data were statistically-analyzed using ANOVA and Tukey's test $(\mathrm{p}<.05)$.
\end{abstract}

Results: Means and standard deviation for proximal contact measurements were: 7.62 (.52), $4.01(.74), 4.13$ (.4) and $2.74(.37)$ for groups $1,2,3$ and 4 respectively. There was a statistical significant difference among all groups except between group2 and 3 .

Conclusions: Under the conditions of this test, it can be concluded that: 1. Proper proximal contact tightness for bulk-fill posterior composite restorations could be produced by sectional metal matrix rather than transparent matrix. 2. Pre-contoured circumferential metal matrix produced the same proximal contact tightness as conventional metal matrix when both used with a separation ring.

KEYWORDS: Bulk-fill Composite, Proximal Contact Tightness, Dental Matrices, Tooth Pressure Meter.

Clinical Relevance Transparent matrices couldn't be recommended for bulk-fill posterior composite restorations rather than metal matrices.

* Associate Professor, Department of Operative Dentistry, Faculty of Dentistry, King Abdulaziz University, Jeddah, Saudi Arabia. Nahda University, Faculty of Dentistry, Conservative Dentistry Department, Beni Suef, Egypt. 


\section{INTRODUCTION}

Nowadays there is an increased emphasis on esthetics in dentistry. This is due to the great evolution of mechanical properties of aesthetic restoratives together with the improvement of adhesive systems. Consequently, tooth-colored materials application in posterior teeth is replacing metallic restorations. Dental composites are becoming the material of choice for direct posterior restorations due to its adhesive capacity which enables the material to be more conservative and to reinforce the restored teeth. Furthermore, certain problems are still faced with posterior dental composites despite of the tremendous improvement in the physical and mechanical properties as well as techniques of placement of such material. Obtaining ideal proximal contacts for posterior composite restorations is one of the challenges that a clinician has to face. This is because of the fact that composite is a non-condensable and has polymerization shrinkage as an inherent property which leads to decreased adaptation at the contact area and contact pressure to adjacent tooth. Failure to obtain ideal contact usually results in food impaction, carious lesions, periodontal complications and tooth migration. ${ }^{[1-4]}$

Recently, reproduction of proper contact point for proximal composite restorations has been developed using different matrix systems. These include pre-contoured matrices, circumferential matrix systems with metal or transparent plastic bands and sectional matrix systems. ${ }^{[3-8]}$

The incremental technique of posterior composites enhances complete polymerization due to light penetration of the material and subsequently reduces overall polymerization shrinkage stresses. However, this technique has the drawback of being time-consuming, therefore manufacturers have launched recently a variety of posterior composite materials which may be applied in single increment up to $4-5 \mathrm{~mm}$ known as "bulk-fill composites" to reduce the time needed for restorations and simplify the restorative procedures especially in large posterior restorations. The placement of these larger increments of bulk-fill composite allows for homogeneous increment thicknesses and thereby reduces technique sensitivity. Therefore, currently, bulk-fill restoratives are clinically preferred. ${ }^{[9-12]}$

This in vitro study evaluated four different matrix systems in measuring the proximal contact tightness achieved in Class II bulk-fill resin composite restorations.

\section{MATERIALS AND METHODS}

Atotal of 80 ivorine lower left first molars (Kilgore International, Coldwater, MI, USA) were used in the current study. Standardized MO-cavity preparation were prepared with the following dimensions; 2.5 x $3.0 \times 4.0 \mathrm{~mm}$ for the occlusopulpal, mesiodistal, and buccolingual respectively in the occlusal part, while the dimensions for the proximal part were 4.0 x 2.0 x $5.0 \mathrm{~mm}$ occlusogingival, mesiodistal and buccolingual respectively. ${ }^{[5,7,13-16]}$ Following cavity preparations, teeth were equally and randomly divided into four equal groups (20 specimens each) according to the type of matrix systems used (Table 1). A separation ring (Composi-tight, Garrison Dental Solutions, USA) was used with all matrices. Wooden wedges (Premier Dental Products, USA) were used to secure different matrices and fitting of matrix band at the gingival margin of the proximal box of each specimen was checked using an explorer. Cavity preparations were restored with bulk-fill composite resin; SonicFill 2 (Kerr Corporation) using the corresponding bonding system following manufacturer's instructions. Composite material was applied in bulk $(4 \mathrm{~mm})$ and cured from occlusal direction at zero distance for 20s using Elipar S10 (3M/ESPE, USA) light curing unit (light intensity $1200 \mathrm{~mW} / \mathrm{cm}^{2}$ ). The light intensity was calibrated every five curing sessions using a radiometer (Demetron, Kerr, USA). No finishing or adjustment was done for restorations to avoid proximal surface changes. A manikin model (Kavo Dental, Germany) 
TABLE (1) Different tested groups for the current study

\begin{tabular}{|c|l|c|c|}
\hline Groups & \multicolumn{1}{|c|}{ Matrix systems } & Thickness & Manufacturer \\
\hline Group1 & Sectional metal matrix & $0.038 \mathrm{~mm}$ thick & Standard matrix, Palodent, Dentsply \\
\hline Group2 & $\begin{array}{l}\text { Pre-contoured circumferential metal matrix in a } \\
\text { Tofflemire retainer }\end{array}$ & $0.038 \mathrm{~mm}$ thick & KerrHawe 1101-c, Kerr Corporation \\
\hline Group3 & Conventional metal matrix in a Tofflemire retainer & $0.038 \mathrm{~mm}$ thick & $\begin{array}{c}\text { Hawe Tofflemire matrices, Kerr } \\
\text { Corporation }\end{array}$ \\
\hline Group4 & $\begin{array}{l}\text { Blue Cure-Thru transparent contoured matrix } \\
\text { band }\end{array}$ & $0.075 \mathrm{~mm}$ thick & Premier Dental Products, USA \\
\hline
\end{tabular}

was used in all restorative procedures to simulate clinical conditions. After matrix and wedge removal, the manikin model was removed from the manikin head after restorative procedures and replaced in a custom-made setup to standardize proximal contact measurements (Figure 1). Proximal contact tightness was measured by the Tooth Pressure Meter (TPM); a device that was invented at the University of Technology Delft in the Netherlands and was previously used in other studies. A metal strip (0.05 mm thick) was used in this device and entered occlusally at interdental area to measure the tightness of the proximal contact when the strip is removed occlusally as the maximum frictional force (N). A special protocol was applied to decrease varieties in proximal contact measurements because of repositioning of the tooth in the manikin model. Three sequential readings were taken for measuring the site and then the mean value was recorded. A measurement is considered to be a failure when the result surpassed the most extreme (preset) range of $0.5 \mathrm{~N}$ between the three readings. A custom composed program in Excel (MS Office 2007 for Windows) was utilized to collect data and develop diagrams relating force to seconds. ${ }^{[5,7,13-17]}$

Statistical analysis was performed with SPSS (SPSS 16, Inc, Chicago, IL, USA) using one-way ANOVA followed by Tukey's post hoc test to determine differences in proximal contact tightness between groups. The level of significance was set at $\mathrm{P}<0.05$.

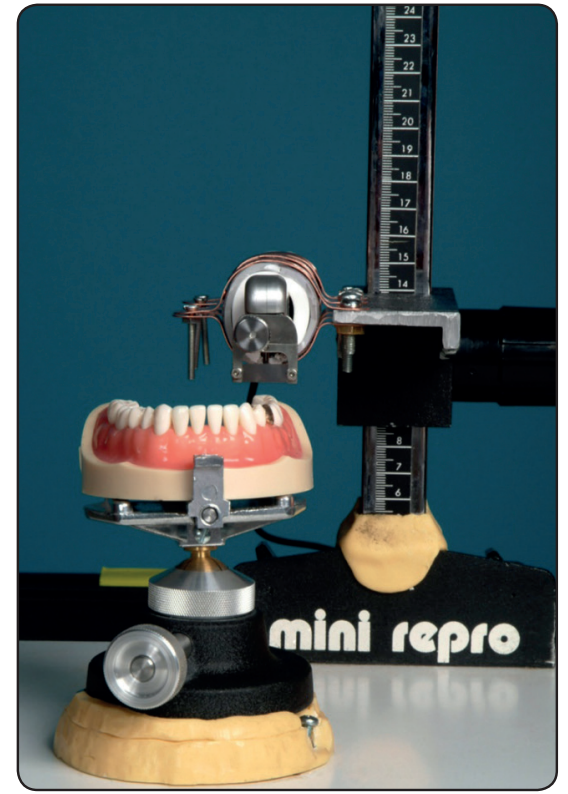

Fig. (1) Custom-made setup for measurements standardization using the Tooth Pressure Meter

\section{RESULTS}

Table (2) shows means and standard deviations (S.D.) of PCT values recorded for the four experimental groups as follows; 7.62 (0.52), 4.01 (0.74), $4.13(0.4)$ and $2.74(0.37)$ for groups 1, 2, 3 and 4 respectively. It is worthy to mention that PCT value recorded for gp1 showed the highest measurement among all the other groups, while the lowest measurement value was recorded by gp4. PCT values for gp2 and gp3 were comparable. (Figure 2)

There was a statistical significant difference $(\mathrm{p}<0.05)$ among all groups except between gp2 and gp3. 
TABLE (2) Means and standard deviations of PCT (N) for the effect of different matrix systems on proximal contact tightness. Different symbols ( $a, b$, and c) indicate statistically significant differences between groups (analysis of variance; $\mathrm{p}<0.05$ ).

\begin{tabular}{|l|c|c|}
\hline \multicolumn{1}{|c|}{ Matrix systems } & Mean \pm S.D. & P \\
\hline $\begin{array}{l}\text { Sectional metal matrix } \\
(\mathrm{Gp} 1)\end{array}$ & $7.62 \pm 0.52$ & $\mathrm{a}$ \\
\hline $\begin{array}{l}\text { Pre-contoured Circumferential } \\
\text { metal (Tofflemire) matrix } \\
\text { (Gp2) }\end{array}$ & $4.01 \pm 0.74$ & $\mathrm{~b}$ \\
\hline $\begin{array}{l}\text { Conventional metal matrix } \\
\text { (Gp3) }\end{array}$ & $4.13 \pm 0.4$ & $\mathrm{~b}$ \\
\hline $\begin{array}{l}\text { Blue Cure-Thru transparent } \\
\text { contoured matrix band } \\
\text { (Gp4) }\end{array}$ & $2.74 \pm 0.37$ & $\mathrm{c}$ \\
\hline
\end{tabular}

S.D. = Standard deviation .

$P \quad=$ Probability level for the effect of groups on the proximal contact tightness.

Same letter within each column are not significantly different at $p<0.05$.



Fig. (2) Mean PCT values for different tested groups

\section{DISCUSSION}

In the present study the influence of different metal versus transparent matrix systems on the PCT of bulk-fill composite restorations was investigated. The design of the current cavity preparation with a wide proximal measurement created an increased challenge to the clinician and the restorative techniques as well in obtaining proper PCT. In the current study, the in-vitro setup used was matching that of several studies and proved to obtain clinically relevant results. ${ }^{[5,7,13-17]}$

The use of separation ring was because it is proved by many clinical and in-vitro studies that the reversible interdental separation is the key in reproducing proper PCT of class II resin composite restorations, they explained this as separation rings create reversible separation force vectors at the proximal contact, which remains stable when the ring is active and relapses when the ring is removed. $[2,7,13,15,18]$

Bulk-fill composites are, currently, clinically preferred as the time needed for restorations is reduced and the restorative procedures are simplified especially in large posterior composite restorations. Manufacturers claimed that bulk-fill composites could be cured up to $4-5 \mathrm{~mm}$ with decreased polymerization shrinkage stresses and increased translucency by decreasing light scattering at the filler-matrix interface. Three different categories for bulk-fill composites are present according to different viscosities; low-viscosity (flowable), variably viscous and highly viscous bulk-fill resin composites. ${ }^{[9,10,11,19]}$ SonicFill 2 is a novel bulkfill composite resin with a special delivery system (special handpiece that produces sonic energy) used to perform filling of cavity preparations in bulk up to $5 \mathrm{~mm}$ by decreasing viscosity (variable viscosity). According to the manufacturer, energy from the SonicFill 2 instrument reduces the composite's viscosity (temporarily reduces the viscosity by $87 \%$ ) in a way that makes it easier for the provider to inject into the tooth's preparation and adapt to 
the tooth surface. The mean application time of composite material with the SonicFill 2 system was 39 seconds versus 3:34 minutes with conventional composite. ${ }^{[20,21]}$

As shown in the results of the current study, sectional matrix showed the highest PCT values with a statistical significant difference $(\mathrm{p}<0.05)$ in relation to the other groups. This was in agreement with the previous studies who found that the use of sectional matrix band with separation ring leads to a very predictable way of achieving ideal proximal contacts. [2-8][13][14][18] This may be explained as in case of sectional matrix, the thickness of the band that will be compensated for better PCT is of course less than the that with the use of circumferential band.

The present study revealed that there was no significant difference $(\mathrm{p}<0.05)$ between precontoured and conventional circumferential metal matrix systems and this may be explained as both systems were in use together with the separation ring in the current study thus may eliminate the differences that may be there due to the precontouring effect. This was in disagreement with other studies who found that pre-contoured matrix bands had tighter proximal contact than flat matrix bands. ${ }^{[22-24]}$

The transparent matrix band revealed the lowest PCT values which were significantly different $(p<0.05)$ from all the other groups; this may be due to the fact that the thickness of the type of the transparent matrix used was increased $(0.075$ mm thick) than that of the other groups. This was in agreement with Müllejans et al in 2003, who explained this as metal matrices are superior in that they can be better adapted and firmly applied to the tooth surface furthermore from an anatomical viewpoint; the metal matrix holds the proximal contour better than its transparent counterpart. ${ }^{[25]}$ Another study found that after 1 year of clinical service, a decrease of proximal contacts quality was shown with restorations placed with transparent matrices. ${ }^{[22]}$ This was in disagreement to other studies who found that there was no significant difference between the metal and the transparent matrix. ${ }^{[1,22,26,27]}$

Proximal contact tightness is used to be evaluated clinically by passing dental floss interdentally and recording the proximal contact tightness as 'satisfactory', 'acceptable' or 'unacceptable'. ${ }^{[28-31]}$ This technique is considered unreliable for measurement of minor changes in contact tightness and is often considered to be more subjective. Therefore, TPM device was used in this study. It was invented at the University of Technology Delft in The Netherlands according to the principles described by Dörfer et al. ${ }^{[32]}$ This device is considered more reliable method to evaluate PCT and has been implemented in many laboratory and clinical studies to objectively measure minor changes. ${ }^{[5-7,13-18,24]}$

\section{Disclosure statement:}

The author declares that he has no conflict of interest.

\section{CONCLUSIONS}

Under the conditions of this study, it was concluded that:

1. Proper proximal contact tightness for bulk-fill posterior composite restorations could be produced by sectional metal matrix rather than transparent matrix.

2. Pre-contoured circumferential metal matrix and conventional metal matrix produced the same proximal contact tightness when both used with a separation ring.

\section{ACKNOWLEDGEMENT}

This project was funded by Deanship of Scientific Research (DSR) at King Abdulaziz University, Jeddah, under grant no. (G711-165-1437). The author, therefore, acknowledges with thanks DSR for technical and financial support. 


\section{REFERENCES}

1. Demarco FF, Pereira-Cenci $T$, de Almeida André D, de Sousa Barbosa RP, Piva E, Cenci MS. Effects of metallic or translucent matrices for Class II composite restorations: 4-year clinical follow-up findings. Clinical Oral Investigation 2011;15(1):39-47.

2. Owens BM, Phebus JG. An evidence-based review of dental matrix systems. General Dentistry 2016;

3. Kampouropoulos D, Paximada C, Loukidis M, Kakaboura A. The influence of matrix type on the proximal contact in Class II resin composite restorations. Operative Dentistry 2010;35(4):454-62.

4. Naz F, Shirazi U-E-R, Khan SR, Tariq U. Choice of Matrix System for Direct Posterior Composites by The Dentists in Lahore. Pakistan Oral \& Dental Journal 2013;33(1).

5. El-Shamy H, Saber M, Dörfer C, El-Badrawy W, Loomans B. Influence of Volumetric Shrinkage and Curing Light Intensity on Proximal Contact Tightness of Class II Resin Composite Restorations: In Vitro Study. Operative Dentistry 2012;37(2):205-10.

6. Wirsching E, Loomans BA, Klaiber B, Dörfer CE. Influence of matrix systems on proximal contact tightness of 2-and 3-surface posterior composite restorations $<\mathrm{i}>$ in vivo</i> . Journal of Dentistry 2011;39(5):386-90.

7. Saber M, Loomans A, Zohairy AE, Dörfer C, El-Badrawy W. Evaluation of proximal contact tightness of Class II resin composite restorations. Operative Dentistry 2010;35(1):37-43.

8. Chuang S-F, Su K-C, Wang C-H, Chang C-H. Morphological analysis of proximal contacts in class II direct restorations with 3D image reconstruction. Journal of Dentistry 2011;39(6):448-56

9. Chesterman J, Jowett A, Gallacher A, Nixon P. Bulk-fill resin-based composite restorative materials: a review. British Dental Journal 2017;222(5):337-44.

10. Yasa B, Kucukyilmaz E, Yasa E, Ertas ET. Comparative study of radiopacity of resin-based and glass ionomerbased bulk-fill restoratives using digital radiography. Journal of Oral Science 2015;57(2):79-85.

11. Dionysopoulos D, Tolidis K, Gerasimou P. The Effect of Composition, Temperature and Post-Irradiation Curing of Bulk Fill Resin Composites on Polymerization Efficiency. Materials Research 2016;(AHEAD):0-0.
12. Agarwal RS, Hiremath H, Agarwal J, Garg A. Evaluation of cervical marginal and internal adaptation using newer bulk fill composites: An in vitro study. Journal of Conservative Dentistry 2015;18(1):56

13. Loomans B, Opdam N, Roeters J, Bronkhorst EM, Plasschaert A. Influence of composite resin consistency and placement technique on proximal contact tightness of Class II restorations. The Journal of Adhesive Dentistry 2006;8(5):305

14. Loomans B, Opdam N, Roeters F, Bronkhorst E, Burgersdijk R, Dörfer C. A randomized clinical trial on proximal contacts of posterior composites. Journal of Dentistry 2006;34(4):292-7.

15. Loomans B, Opdam N, Roeters F, Bronkhorst E, Burgersdijk R. Comparison of proximal contacts of Class II resin composite restorations in vitro. Operative Dentistry 2006;31(6):688-93.

16. Saber M, El-Badrawy W, Loomans B, Ahmed D, Dörfer C, El Zohairy A. Creating tight proximal contacts for MOD resin composite restorations. Operative Dentistry 2011;36(3):304-10.

17. Loomans BAC, Opdam NJM, Roeters FJM, Bronkhorst EM, Plasschaert AJM. The long-term effect of a composite resin restoration on proximal contact tightness. Journal of Dentistry 2007;35(2):104-8

18. Loomans B, Opdam N, Roeters E, Bronkhorst F, Dörfer C. A clinical study on interdental separation techniques. Operative Dentistry 2007;32(3):207-11.

19. Benetti A, Havndrup-Pedersen C, Honoré D, Pedersen M, Pallesen U. Bulk-fill resin composites: polymerization contraction, depth of cure, and gap formation. Operative Dentistry 2015;40(2):190-200.

20. Hirata R, Caceres E, Pacheco R, Janal M, Romero M, Rueggeberg $\mathrm{F}$, et al. Internal void formation on dental composites using ultra-sonic devices. Dental Materials 2015;31:e6.

21. Abourezq IA. Voids in Sonic Fill ${ }^{\mathrm{TM}}$ restorations compared to traditional incrementally-filled composite restorations. Temple University; 2014

22. Demarco FF, Cenci MS, Lima FG, Donassollo TA, André D de A, Leida FL. Class II composite restorations with metallic and translucent matrices: 2-year follow-up findings. Journal of Dentistry 2007;35(3):231-7.

23. Prakki A, Otávio Chalup Saad J, Rodrigues JR. Clinical 
evaluation of proximal contacts of Class II esthetic direct restorations. Quintessence International 2004;35(10).

24. Loomans B, Roeters F, Opdam N, Kuijs R. The effect of proximal contour on marginal ridge fracture of Class II composite resin restorations. Journal of Dentistry 2008;36(10):828-32.

25. Mullejans R, Badawi M, Raab W, Lang H. An in vitro comparison of metal and transparent matrices used for bonded class II resin composite restorations. Operative Dentistry 2003;28(2):122-6.

26. Boksman L. Matrix systems and the Class II composite resin. Oral health Journal 2010;

27. Cenci MS, Demarco FF, Pereira CL, Lund RG, others. One-year comparison of metallic and translucent matrices in Class II composite resin restorations. American Journal of Dentistry 2007;20(1):41-5.
28. Abrams H, Kopczyk RA. Gingival sequela from a retained piece of dental floss. Journal of the American Dental Association (1939) 1983;106(1):57-8.

29. Ryge G. Clinical criteria. International Dental Journal 1980;30(4):347-58.

30. Teich ST, Joseph J, Sartori N, Heima M, Duarte S. Dental Floss Selection and Its Impact on Evaluation of Interproximal Contacts in Licensure Exams. Journal of Dental Education 2014;78(6):921-6.

31. Dörfer CE, Wündrich D, Jörg Staehle H, Pioch $T$. Gliding capacity of different dental flosses. Journal of Periodontology 2001;72(5):672-8.

32. Dörfer CE, Von Bethlenfalvy ER, Staehle HJ, Pioch T. Factors influencing proximal dental contact strengths. European Journal of Oral Sciences 2000;108(5):368-77. 